\title{
Participation of the $\beta$-Ketoadipate Transport System in Chemotaxis
}

\author{
By MAHMOUD KARIMIAN AND L. NICHOLAS ORNSTON* \\ Department of Biology, Yale University, New Haven, Connecticut 06520, U.S.A.
}

(Received 8 October 1980; revised 24 November 1980)

\begin{abstract}
$\beta$-Ketoadipate serves as a chemoattractant for Pseudomonas putida. The chemotactic response is inducible, and a regulatory mutant strain that forms the $\beta$-ketoadipate transport system at high levels exhibits a heightened chemotactic response to $\beta$-ketoadipate. Adipate and succinate, compounds that interact with the transport system, inhibit chemotaxis toward $\beta$-ketoadipate. Some, but not all, mutants that fail to respond chemotactically to $\beta$-ketoadipate lack the $\beta$-ketoadipate transport system. It thus appears that the transport of $\beta$-ketoadipate is associated with its function as a chemoattractant. It is likely that the metabolite attracts fluorescent Pseudomonas species to environments in which complex aromatic polymers undergo microbial dissimilation.
\end{abstract}

\section{IN TRODUCTION}

Members of fluorescent Pseudomonas species form an inducible transport system that acts on $\beta$-ketoadipate (Ornston \& Parke, 1976). The system is not formed at a level sufficient to permit the efficient utilization of exogenous $\beta$-ketoadipate as a growth substrate (Stanier, 1950; Ondrako \& Ornston, 1980). Nevertheless, the system appears to have selective value because it has been conserved in divergent Pseudomonas species (Ondrako \& Ornston, 1980). In this report we summarize evidence leading to the conclusion that the transport system has been conserved in evolution because it is a component of a mechanism that allows $\beta$-ketoadipate to act as a chemoattractant.

\section{METHODS}

Strains. Wild-type Pseudomonas putida strain PRS2000 and the constitutive mutant strain PRS2178 have been described elsewhere (Ondrako \& Ornston, 1980). The regulatory mutation in strain PRS2178 causes elevated expression of the $\beta$-ketoadipate transport system and constitutive synthesis of the three enzymes that give rise to $\beta$-ketoadipate from $\beta$-carboxy-cis,cis-muconate (Parke \& Ornston, 1976). Mutant strains deficient in $\beta$-ketoadipate taxis were selected from strain PRS2178 on the basis of their inability to swarm in response to gradients created on semi-solid agar plates (Armstrong et al., 1967) containing $10 \mathrm{~mm}$ - $\beta$-ketoadipate. Cells that failed to migrate from the centre of the plates were placed on semi-solid agar plates containing $10 \mathrm{~mm}$ citrate. Cells that formed a ring in response to the citrate gradient were picked, grown in liquid culture with glucose, and spotted once more on semi-solid agar plates containing $10 \mathrm{~mm}$ - $\beta$-ketoadipate. After repeated transfers, reduced swarming and dense bacterial growth at the origin were observed on the $\beta$-ketoadipate plates. Organisms from the origin were purified by single colony isolation on non-selective media; the isolated strains were examined for chemotaxis, the presence of the $\beta$-ketoadipate transport system, and constitutive synthesis of the three enzymes that give rise to $\beta$-ketoadipate from $\beta$-carboxy-cis,cis-muconate.

Culture conditions. Cells were maintained at $30^{\circ} \mathrm{C}$ during growth and chemotaxis experiments. Cultures grown in defined medium (Ornston \& Stanier, 1966) were harvested by centrifugation for $10 \mathrm{~min}$ at $3000 \mathrm{~g}$, washed twice with chemotaxis buffer $(0.05 \mathrm{M}$-sodium phosphate buffer containing $10 \mu \mathrm{M}$-EDTA, pH 7.0) and resuspended in chemotaxis buffer. Chemotaxis was observed qualitatively as the formation of expanding rings of growth in response to chemical gradients created on semi-solid agar plates containing defined growth medium and $0.3 \%(\mathrm{w} / \mathrm{v})$ Difco agar (Armstrong et al., 1967). The plates were maintained in a water-saturated incubator. 

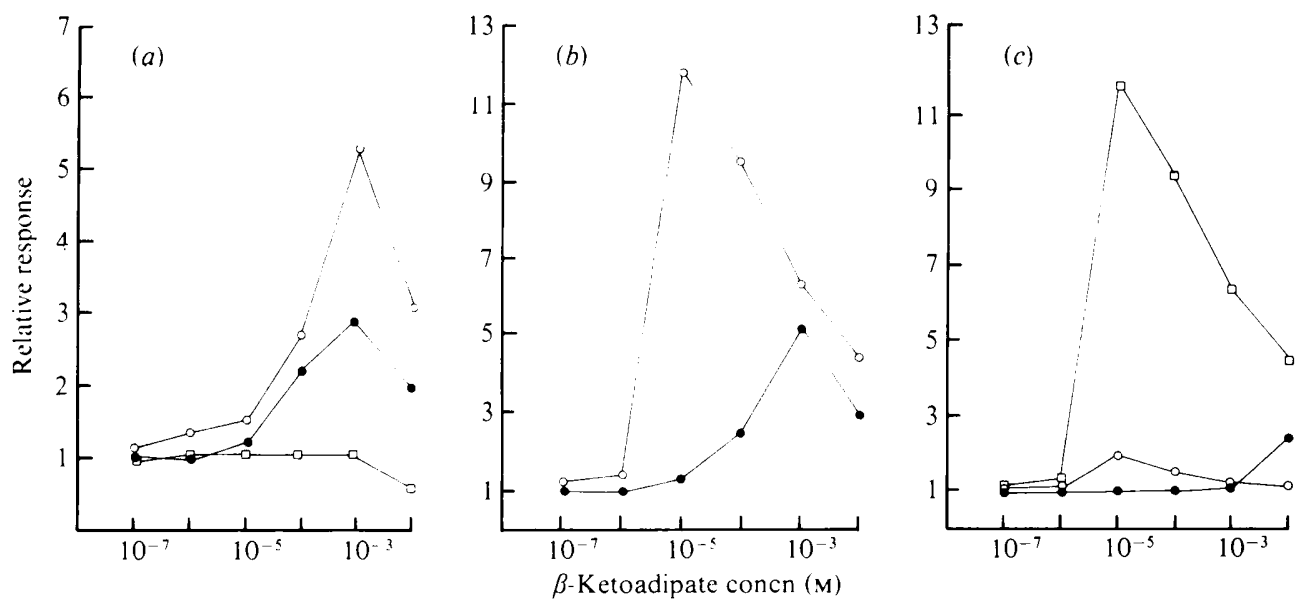

Fig. 1. (a) Induction and repression of $\beta$-ketoadipate taxis in wild-type $P$. putida strain PRS2000 grown with $p$-hydroxybenzoate $(O)$, succinate $(\square)$ or glucose $(\bigcirc)$. A relative response of 1 corresponds to $5 \times 10^{4}$ cells per capillary, the number observed in capillaries lacking chemoattractant.

(b) $\beta$-Ketoadipate taxis of the uninduced transport-constitutive mutant strain PRS2178 grown with glucose (O), compared with the induced wild-type strain PRS2000 grown with $p$-hydroxybenzoate (O).

(c) Inhibition of $\beta$-ketoadipate taxis of glucose-grown strain PRS2178 by 0.4 mM-adipate (O) and $1 \mathrm{~mm}$-succinate $(\mathbf{O})$, compared with taxis in the absence of inhibitor $(\square)$.

Quantitative chemotaxis assay. Washed cultures were diluted to a concentration of $1.7 \times 10^{7} \mathrm{cells}^{\mathrm{ml}} \mathrm{m}^{-1}$ in chemotaxis buffer. Capillary assays were performed for $30 \mathrm{~min}$ at $30^{\circ} \mathrm{C}$ by the method of Adler (1973). The reported number of cells in capillaries is the average of five determinations. Cells were counted as colony-forming units on succinate plates.

Assay of enzymes and the $\beta$-ketoadipate transport system. The specific activities of enzymes were determined by previously described procedures (Ornston, 1966). Radioactive adipate, a non-metabolizable analogue of $\beta$-ketoadipate, was used to measure the activity of the $\beta$-ketoadipate transport system (Ondrako \& Ornston, 1980).

\section{RES ULTS}

Chemotaxis toward $\beta$-ketoadipate is inducible in wild-type bacteria. The $\beta$-ketoadipate transport system is induced by growth of wild-type $P$. putida with $p$-hydroxybenzoate, a compound that is metabolized via $\beta$-ketoadipate; synthesis of the transport system is repressed by growth with succinate (Parke \& Ornston, 1976). As shown in Fig. 1(a), wild-type $P$. putida responded chemotactically to $\beta$-ketoadipate, and the tactic response was induced by growth with $p$-hydroxybenzoate. A significant chemotactic response was observed with cells that had been grown with the non-repressing carbon source glucose, whereas succinate-grown cells did not respond chemotactically to $\beta$-ketoadipate (Fig. $1 a$ ).

Mutations causing heightened $\beta$-ketoadipate transport activity lead to an elevated chemotactic response. Glucose-grown cultures of the constitutive mutant strain PRS2178 form the $\beta$-ketoadipate transport system at a level about 10 -fold higher than that found in induced wild-type cells (Parke \& Ornston, 1976). The regulatory mutation in strain PRS2 178 also caused a heightened chemotactic response to $\beta$-ketoadipate. As shown in Fig. $1(b)$, the response of uninduced constitutive cells was higher than that of the induced wild-type cells. The threshold of response to $\beta$-ketoadipate was somewhat lower than $10 \mu \mathrm{M}$ (Fig. $1 b$ ). This concentration does not differ greatly from $40 \mu \mathrm{M}$, the $K_{\mathrm{i}}$ observed with $\beta$-ketoadipate as a competitive inhibitor of adipate transport by the system (Ondrako \& Ornston, 1980). 
Table 1. Taxis and transport in mutant strains of P. putida

\begin{abstract}
Mutant strains were selected from strain PRS2178 on the basis of their inability to migrate in response to a gradient of $\beta$-ketoadipate. All the strains exhibited citrate and succinate taxis on semi-solid agar plates. The taxis mutants, like their parental strain PRS2178, formed constitutively the three enzymes that convert $\beta$-carboxy-cis,cis-muconate to $\beta$-ketoadipate. Taxis was determined (5 determinations) with $10 \mu \mathrm{M}$ - $\beta$-ketoadipate, and transport activity was determined with $\left[{ }^{14} \mathrm{Cladipate}\right.$.
\end{abstract}

$\begin{array}{ccc}\text { Strain } & \begin{array}{c}\beta \text {-Ketoadipate taxis } \\ \left(10^{-4} \times \text { no. of cells }\right. \\ \text { per capillary } \pm \text { S.D. })\end{array} & \begin{array}{c}\text { Rate of adipate transport } \\ {\left[\text { pmol }(\mathrm{mg} \mathrm{dry} \mathrm{wt})^{-1} \mathrm{~min}^{-1}\right]}\end{array} \\ \text { PRS2178 } & 56 \pm 2 \cdot 2 & 350 \\ \text { PRS2261 } & 5 \pm 0.5 & 10 \\ \text { PRS2262 } & 6 \pm 0.6 & 18 \\ \text { PRS2263 } & 5 \pm 0.5 & 320\end{array}$

Adipate and succinate inhibit $\beta$-ketoadipate chemotaxis. Adipate and succinate both interact with the $\beta$-ketoadipate transport system. Adipate is a non-metabolizable analogue that normally is used to measure the activity of the transport system in P. putida (Ornston \& Parke, 1976); the $K_{\mathrm{m}}$ of the system for adipate is about $0.2 \mathrm{~mm}$ (Ondrako \& Ornston, 1980). Succinate competitively inhibits the transport system with a $K_{\mathrm{i}}$ of $1.3 \mathrm{~mm}$ (Ondrako \& Ornston, 1980). As shown in Fig. $1(c)$, both $0.4 \mathrm{mM}$-adipate and $1 \mathrm{~mm}$-succinate inhibited the chemotactic response of $P$. putida to $\beta$-ketoadipate.

Selection for absence of the chemotactic response yields mutant strains lacking the transport system. Taxis-deficient mutant strains were selected from strain PRS2178 on the basis of their inability to respond chemotactically to $\beta$-ketoadipate. Two of the mutant strains had dysfunctions in the $\beta$-ketoadipate transport system (Table 1). Another mutant strain was defective in $\beta$-ketoadipate taxis but retained an active $\beta$-ketoadipate transport system (Table 1). Thus it appears that some activities required for $\beta$-ketoadipate taxis may be traced directly to the transport system and that one or more additional components are associated with the tactic response.

\title{
DISCUSSION
}

Kinetic, physiological and genetic evidence points to the conclusion that the $\beta$-ketoadipate transport system is a component of a mechanism that allows $\beta$-ketoadipate to serve as a chemoattractant for fluorescent Pseudomonas species. The activity of the $\beta$-ketoadipate transport system may be recovered in membrane vesicles (Ondrako \& Ornston, 1980). Therefore the common $\beta$-ketoadipate taxis-transport component cannot be a periplasmic binding protein of the type associated with carbohydrate taxis and transport in coliform bacteria (Hazelbauer \& Adler, 1971; Aksamit \& Koshland, 1974; Hazelbauer, 1975). By analogy with the membrane-associated phosphotransferase enzyme for glucose (Adler \& Epstein, 1974), it might be suggested that the transport of $\beta$-ketoadipate is vectorial, forming a product like $\beta$-ketoadipyl-CoA. This seems unlikely because the vesicular transport of $\beta$-ketoadipate may be driven by respiratory energy in the absence of CoA (Ondrako \& Ornston, 1980). Furthermore, mutations that block the intracellular conversion of $\beta$ ketoadipate to $\beta$-ketoadipyl-CoA prevent the utilization of exogenous $\beta$-ketoadipate (Wallis, Ondrako \& Ornston, unpublished observations). Thus it appears that the component shared in $\beta$-ketoadipate transport and taxis is unique among known systems.

Little direct nutritional benefit is conferred by the $\beta$-ketoadipate transport system, and its primary selective value probably lies in the contribution it makes to chemotaxis. This raises the question of why the bacteria are attracted to a poor growth substrate like $\beta$ ketoadipate. The answer may lie in the fact that $\beta$-ketoadipate accumulates as aromatic compounds are dissimilated by microbial cultures (Kilby, 1951). $\beta$-Ketoadipate may confer 
an indirect nutritional benefit by serving as a relatively simple chemical signal attracting fluorescent pseudomonads to environments in which the microbial breakdown of complex aromatic polymers is underway.

We thank May Kihara and Robert Macnab for valuable advice throughout this investigation. The research was supported by Public Health Service Grant GM25487 and by National Science Foundation Grant PCM7724884. M. Karimian was a scholar of the Iranian Ministry of Science and Education.

\section{REFERENCES}

AdLER, J. (1973). A method for measuring chemotaxis and use of the method to determine optimum conditions for chemotaxis by Escherichia coli. Journal of General Microbiology 74, 77-91.

AdLER, J. \& EPSTEIN, W. (1974). Phosphotransferasesystem enzymes as chemoreceptors for certain sugars in Escherichia coli chemotaxis. Proceedings of the National Academy of Sciences of the United States of America 71, 2895-2899.

AKsamit, R. R. \& Koshland, D. E., JR (1974). Identification of the ribose binding protein as the receptor for ribose chemotaxis in Salmonella typhimurium. Biochemistry 13, 4473-4478.

ARMSTRonG, J. B., AdLer, J. \& DAHL, M. M. (1967). Nonchemotactic mutants of Escherichia coli. Journal of Bacteriology 93, 390-398.

HAZElbauer, G. L. (1975). Maltose chemoreceptor of Escherichia coli. Journal of Bacteriology 122, 206-214.

Hazelbauer, G. L. \& Adler, J. (1971). Role of the galactose binding protein in chemotaxis of Escherichia coli toward galactose. Nature New Biology 230, 101-104.

KILBY, B. A. (1951). The formation of $\beta$-ketoadipic acid by bacterial fission of aromatic rings. Biochemical Journal 49, 671-674.

Ondrako, J. M. \& ORnston, L. N. (1980). Biological distribution and physiological role of the $\beta$ ketoadipate transport system. Journal of General Microbiology 120, 199-209.

ORNSTON, L. N. (1966). The conversion of catechol and protocatechuate to $\beta$-ketoadipate by Pseudomonas putida. II. Enzymes of the protocatechuate pathway. Journal of Biological Chemistry 241, 3787-3794.

Ornston, L. N. \& PARKe, D. (1976). Properties of an inducible uptake system for $\beta$-ketoadipate in Pseudomonas putida. Journal of Bacteriology 125, 475-488.

Ornston, L. N. \& Stanier, R. Y. (1966). The conversion of catechol and protocatechuate to $\beta$-ketoadipate by Pseudomonas putida. I. Biochemistry. Journal of Biological Chemistry 241, 3776-3786.

PARKe, D. \& ORnSton, L. N. (1976). Constitutive synthesis of enzymes of the protocatechuate pathway and of the $\beta$-ketoadipate uptake system in mutant strains of Pseudomonas putida. Journal of Bacteriology 126, 272-281.

Stanier, R. Y. (1950). Problems of bacterial oxidative metabolism. Bacteriological Reviews 14, 179-191. 